\title{
Comparative study of teaching natural delivery benefits and optimism training on mothers' attitude and intention to select a type of delivery: an educational experiment
}

\author{
Mahin Esmaeili Darmian ${ }^{1}$, Sedigheh Yousefzadeh², Tahereh Fathi Najafi ${ }^{3}$, Seyyed Vahid Javadi ${ }^{4}$
}

${ }^{1}$ M.Sc. of Midwifery, Lecturer, Department of Midwifery, Birjand Medical Sciences Branch, Islamic Azad University, Birjand, Iran

${ }^{2}$ M.Sc. of Midwifery, Lecturer, Department of Midwifery, School of Nursing and Midwifery, Mashhad University of Medical Sciences, Mashhad, Iran

${ }^{3}$ Ph.D. of Reproductive Health, Department of Midwifery, Mashhad Medical Sciences Branch, Islamic Azad University, Mashhad, Iran

${ }^{4}$ M.A. of Educational Psychology, Faculty of Education and Psychology, Birjand University, Birjand, Iran

Type of article: Original

\begin{abstract}
Background: Despite advantages of normal vaginal delivery (NVD) and disadvantages of caesarean section (Csection) and the increasing C-section rate Iran, appropriate training is essential in reducing this trend. Optimism is one of the important psychological determinants which is a combination of positive desire and attitude in people.

Objective: The purpose of this study was to determine the effects of optimism training as well as training the benefits of natural childbirth on attitude and intentions to choose the type of delivery.

Methods: In this experimental study, 96 primiparous women referring to health centers in Mashhad (Iran) in 2014 with pregnancy duration of 30 to 34 weeks and without indication of C-section, were selected and randomly divided into two training groups and one control group. Optimism training was provided during six 60 -minute sessions, whereas training the benefits of NVD was conducted in four 60-minute sessions. Pre-test and post-test were performed using valid and reliable questionnaires, researcher-made questionnaire, attitude-measuring questions on NVD and C-section, and optimism-measuring standard questionnaires (LOT-R). Data were analyzed by IBM-SPSS version 22, using Kruskal-Wallis, Chi square, paired-samples t-test, Independent-samples t-test, Man-Whitney U, and Wilcoxon signed-rank test.

Result: There was a significant difference between the mean scores of attitudes towards natural delivery in the group that received both optimism and natural delivery advantages trainings compared with the group receiving only the latter $(\mathrm{p}>0.001)$. Frequency of intentions to choose the type of delivery after optimism and natural delivery advantages trainings compared with training the benefits of natural childbirth only, did not show a significant difference $(\mathrm{p}=0.135)$.

Conclusion: Optimism training combined with training the benefits of natural childbirth is more effective in creating positive attitude towards natural delivery in comparison with only the NVD advantages education, but it has no effect on selecting the type of delivery. Probably one of the most important reasons of failure of achieving a proper result is the low sample size.

Trial registration: The trial was registered at the Iranian Registry of Clinical Trials (http://www.irct.ir) with the Irct ID: IRCT2015063022995N1.

Funding: This trial is funded by Mashhad University of Medical Sciences in collaboration with the EvidenceBased Research Center (Ref: research/930321/1/172).

Keywords: Education, Optimism, Normal vaginal delivery, Caesarean section, Intention, Attitude
\end{abstract}

\section{Corresponding author:}

Sedigheh Yousefzadeh, Department of Midwifery, School of Nursing and Midwifery, Mashhad University of Medical Sciences, Mashhad, Iran. Tel: +98.9153202371, Email: YousefzadehS@mums.ac.ir

Received: October 26, 2017, Accepted: April 12, 2018, Published: July 2018

iThenticate screening: April 05, 2018, English editing: June 26, 2018, Quality control: July 10, 2018

This article has been reviewed / commented by three experts

Funding / research project approval: research/930321/1/172 (Mashhad University of Medical Sciences)

Ethics approval: 930321 (Mashhad University of Medical Sciences)

(C) 2018 The Authors. This is an open access article under the terms of the Creative Commons Attribution-NonCommercialNoDerivs License, which permits use and distribution in any medium, provided the original work is properly cited, the use is non-commercial and no modifications or adaptations are made. 


\section{Introduction}

The mechanism of childbirth consists of an automatic process without any need of intervention and only in situations at which the mother or the child's lives are in danger, should caesarean section (C-section) be performed for the safety of mother and child $(1,2)$. Natural childbirth has several advantages over C-section, some of which are it being cost effective, requiring less time of stay in hospital, no need for anesthesia and also, there is less possibility of maternal bleeding, infection and mortality (3). According to a WHO report, only 10-15\% of all childbirths should lead to C-section, however currently 50-65\% of childbirths in Iran are done by C-section, $90 \%$ of which are conducted in private hospitals (4-9). According to studies conducted in Iran, more than 70\% of pregnant women choose to perform $\mathrm{C}$-section for unnecessary reasons. These women may opt for $\mathrm{C}$-section due to reasons such as avoiding the pain or because of a widespread unfounded fear among the general population as a result of lack of knowledge of delivery processes (10-12). Another important factor in C-section increase is socioeconomic conditions led by psychological stress and negative attitude towards the previous natural birth (13). Sharifirad (14) has also reported that about $70 \%$ of women take negative attitudes towards natural birth, and that educational programs must be organized for women. The mother's satisfaction of childbirth experience greatly depends on her choice of delivery type (2). Studies have demonstrated that the most effective method for improving the results and quality of treatments and care (excluding emergency cases) is involving the patient in the decision processes (15, 16). Gamble et al. (17), have also emphasized the fact that women must be assisted in making correct decisions through education and socio psychological support. However, in the process of making the decisions, the decision maker's attitudes in interpretation and assessment of information plays a major role, and education will be deemed effective when it can result in a positive change of attitude, so that finally the safest and the best delivery method that is also suited with the situation is selected $(7,18)$. Waldernstrom et al. (19) have shown in their study that less educated women whose negative attitude towards natural birth have remained unchanged, have selected $\mathrm{C}$-section $(3$ to 6 times more frequently than others) as their desired method of delivery. Therefore, it seems that natural childbirth is a stressful event that requires a type of psychological compatibility. One of the important determiners of psychological compatibility that is also a combination of desire and positive attitude in people, is optimism (20).

Optimism and pessimism are main qualities of personality, and affect the compatibility of people with life's events. Studies have shown that optimism results in less depression, less discomfort and indeed better and healthier delivery in pregnant women. Optimism has a reverse relation with stress and pessimistic people suffer from stress. Women with optimism experience less stress and strain during pregnancy and will be able to resist them more efficiently (21, 22). Bar et al. (23) in a study on optimism and its effects on delivery type, found that pessimism is related to Csection increase, whereas optimism had no effect on C-section rate. Mayer et al., (24) in another study, showed that in comparison with pessimism, optimism leads to more relaxation during labor by means of improving stressopposing ways; therefore resulting in a reduction of the lack of delivery progress and a decrease in unplanned Csection rates. Although natural delivery is not always recommended as the best delivery method due to increase in $\mathrm{C}$-section rate, its percentage has shown a decreasing trend during recent years. Considering the fact that conduction of unnecessary C-sections leads to increase in mortality, side effects in mothers and babies and also imposes economic costs on society (4), it is therefore proper to make more effort in promoting normal vaginal delivery (NVD) by providing guidance and education for pregnant women. The aim of this study was to determine the effects of providing education on optimism and benefits of natural birth on pregnant women's attitude and choice of delivery type.

\section{Material and Methods}

\subsection{Research Design}

This study was an educational experimental study that was conducted on 96 primiparous women referring to health centers in Mashhad (Iran) in 2014.

\subsection{Sampling}

\subsubsection{Sample size}

The sample volume was based on a Shahraki et al. study (25). The success rate was $22 \%$ for the group receiving education and $4 \%$ for the group without education. Considering the maximum acceptable error of $20 \%$, the sample volume was calculated to be 32 for each group.

\subsubsection{Sampling method}

Health centers were selected by multistage sampling. First, five health centers in Mashhad city were chosen. Since health center No. 3 was made up of almost half of the population of Mashhad, it was allocated to one category, while the other centers were classified into different categories. Then, by proportional-to-size sampling, four health centers were selected (two centers in each category). Using the random numbers table, one center from each of the 
two categories was selected to receive training on the benefits of natural childbirth. The other two centers were considered as control. Participants were selected by convenience sampling based on inclusion criteria and the objectives of the study. Figure 1 shows the study flow diagram.

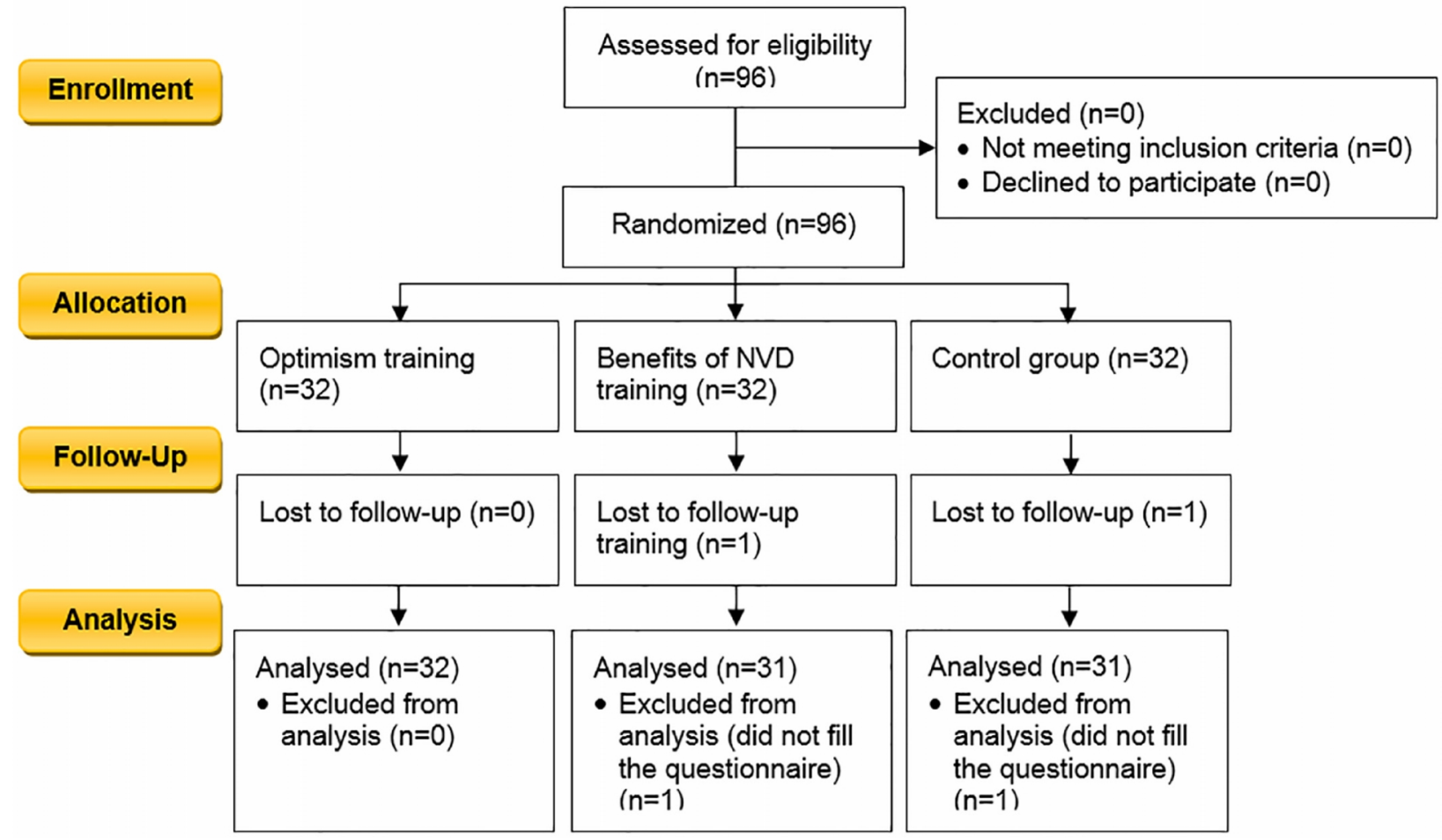

Figure 1. CONSORT 2010 Flow Diagram of the study

\subsection{Selection criteria}

2.3.1. Inclusion criteria

The following were set as the inclusion criteria: 1) primigravity with singleton pregnancy; 2) gestational age of 30 34 weeks; 3) age of 18-35 years; 4) no history of infertility; 5) no obstetric indications for C-section and 6) lack of continuous training about the mode of delivery.

2.3.2. Exclusion criteria

The exclusion criteria were: 1) presence of medical conditions, 2) abnormal or non-viable fetus based on the ultrasound, 3) abnormal volume of amniotic fluid, and 4) abnormal placental placement.

\subsection{Measurement tools}

The utilized tools in this study include: personal-pregnancy information form (15 questions), researcher-made questionnaire including 14 attitude measuring questions on normal and C-section and a check list of delivery method selection assessment (2 questions), optimism measuring standard questionnaires (LOT-R) (10 questions). Attitude measuring questionnaires are to determine the attitude towards normal and $\mathrm{C}$-section deliveries, which are categorized based on a 5-point Likert scale (Fully agree, agree, no opinion, disagree, and fully disagree). In the present study, the reliability of the attitude measuring questionnaires of normal and C-section were calculated and verified by calculating Cronbach's alpha coefficient of 0.94 and 0.93 , respectively. The check list of delivery method selection assessment was used to register the pregnant woman's decision on delivery type, before and after the study, and includes 2 questions of the pregnant woman's decision on delivery type and the doctor's recommendation regarding this. The optimism measuring questionnaires (LOT-R) include 10 questions, 3 of which are positive and are scored directly, these question numbers are 1, 4 and 10. Scoring 5-option questions with grades from fully agree to agree, no opinion, disagree and fully disagree will be done with 0-4 points. In the present study of reliability coefficient, Cronbach's alpha of 0.80 was obtained. The questionnaires and check lists' validity were determined based on content validity using literature review and obtaining the opinion of specialists and experts of this area.

\subsection{Intervention and data collection}

After obtaining informed consent from research units, the questionnaires were filled by them. At centers that only received education on the advantages of NVD, the educational materials were provided during four one-hour 
sessions, each once a week, in the form of lectures using PowerPoint presentation with personal laptops. Ten minutes of each session was specified for break and also the last 15 minutes of each session was considered for answering the research units' questions. Moreover, during this time the researcher contacted research units before each session and reminded them of the procedure. The educational material is comprehensively described as the following:

1) First session:

General information on labor stages (stages zero, one, two and three), different types of delivery (NVD, C-section, using tools) along with picture display and also a brief description of the used indication of each method.

2) Second session:

Description of advantages and disadvantages of $\mathrm{C}$-section for mothers and babies along with pictures and video display.

3) Third session:

Description of advantages and disadvantages of NVD for mothers and babies along with pictures and video display.

4) Forth session:

Introduction of painless and low pain delivery methods along with picture display. Moreover, active exercises of Csection disadvantages and NVD advantages in the form of matching flash cards containing these items were used in the appropriate category. At the end of the session, a brief description was provided on the process of vaginal examination and the conduction of episiotomy as well as its repair, moreover, the research units were given educational pamphlets with the title of 'C-section or NVD?'.

Optimism and NVD advantages education was conducted during six 60-minute sessions with the participation of a group of research units in the form of lectures and discussions including examples and exercises whose material was adapted and developed from 'Seligman's learned theory of optimism'.

1) First session:

Review of the session's construction and main rules and introduction of research units to each other, education on different delivery types (C-section, NVD) as well as the advantages and disadvantages of each.

2) Second session:

Discussion on the two concepts of optimism and pessimism and their effects of life as well as the characteristics of optimistic and pessimistic people.

3) Third session:

Stating the relations between thoughts and feelings and unfortunate events (introduction to the 3 -column table of $\mathrm{ABC}$ and how to fill it. ' $\mathrm{A}$ ' meaning event and by event it was meant a happening that occurs before belief or thought. ' $\mathrm{B}$ ' is a belief or thought forming after the event. ' $\mathrm{C}$ ' is the consequence of event and is the feeling of anxiety and worry (active exercise).

4) Forth session:

Introduction to negative unintentional thoughts and irrational beliefs along with examples on delivery types (active exercise).

5) Fifth session:

Documentary modification: changing ways of pessimistic explanation (internal, general and stable) to optimistic ones (external, special and transient).

6) Sixth session:

Education on how to deal with negative and pessimistic thought (active exercise). During this time, the control group was receiving routine prenatal care.

At the end of the final session, for third groups, the questionnaires of attitudes towards C-section and NVD as well as check lists of delivery method selection assessment were filled by the pregnant women. A member of the NVD advantages education group was excluded from the study due to her absence in the final session and therefore missing the final test.

\subsection{Data analyze}

Data analysis was performed in IBM@ SPSS $\odot$ Statistics version 22 (IBM $\odot$ Corp., Armonk, NY, USA) using Kruskal-Wallis, Chi square, paired-samples t-test, Independent-samples t-test, Man-Whitney U, and Wilcoxon signed-rank test (significance level of $\mathrm{p}<0.05$ ).

\subsection{Research Ethics}

This study approved by the Ethics Committee of School of Nursing and Midwifery, Mashhad University of Medical Sciences (Ref: 930321). Participation in the research was voluntary, and written informed consent was taken from 
all participants. Furthermore participants were informed that if at any time, they did not desire to continue cooperation, they could be excluded.

\section{Results}

The average age of the research units was $25.53 \pm 3.3$ years. In total, $83 \%$ of them were housewives and the other $17 \%$ were employed. The education level of most of them was high school and diploma (44.66\%). In most research units, the educational level of husbands was also high school and diploma (38.4\%), and a number were shop clerks $(63.86 \%)$. Both groups had similar conditions in terms of age, participant and her spouse's educational level, income, delivery type information obtaining source, using insurance, type of insurance, number of visits for prenatal care and the visiting place for this purpose. In order to assess the frequency of delivery type selection intent of pregnant women before and after the intervention, these three groups were tested and compared using KruskalWallis tests and in each group using Wilcoxon signed-rank test. The results demonstrated that after the intervention, the three groups did not show a significant statistical difference in terms of frequency of delivery type selection intent $(\mathrm{p}=0.135)$. In the group that received both optimism and NVD advantages education, the delivery type selection intent showed a significant difference before and after the intervention $(\mathrm{p}=0.006)$. In the NVD advantages education group, a significant difference was also observed in the delivery type selection intent before and after the intervention $(\mathrm{p}=0.004)$ (Table 1). In order to assess the attitude towards $\mathrm{C}$-section before and after the intervention in the three groups, variance analysis (for normally distributed variables) and Kruskal-Wallis (for non-normally distributed variables) tests were used (Table 2).

Table 1. Frequency distribution of delivery type selection intent before and after the intervention with separation of the three studied groups

\begin{tabular}{|c|c|c|c|c|c|c|c|c|}
\hline \multirow{2}{*}{\multicolumn{2}{|c|}{ delivery type selection intent }} & \multicolumn{2}{|c|}{ Optimism training } & \multicolumn{2}{|c|}{$\begin{array}{l}\text { Training the benefits } \\
\text { of NVD }\end{array}$} & \multicolumn{2}{|c|}{ Control } & \multirow[t]{2}{*}{$\begin{array}{l}\text { Intra-group } \\
\text { test results }\end{array}$} \\
\hline & & $\%$ & $\mathrm{n}$ & $\%$ & $\mathrm{n}$ & $\%$ & $\mathrm{n}$ & \\
\hline \multirow{5}{*}{$\begin{array}{l}\text { Before } \\
\text { intervention }\end{array}$} & Definitely C.S. & 12.5 & 4 & 3.2 & 1 & 16.1 & 5 & \multirow{5}{*}{$\begin{array}{l}X^{2}=0.20 \\
p=0.906\end{array}$} \\
\hline & Probably C.S. & 31.3 & 10 & 32.3 & 10 & 32.3 & 10 & \\
\hline & Probably NVD & 28.1 & 9 & 45.2 & 14 & 19.4 & 6 & \\
\hline & Definitely NVD & 28.1 & 9 & 19.4 & 6 & 32.3 & 10 & \\
\hline & Total & 100.0 & 32 & 100.0 & 31 & 100.0 & 31 & \\
\hline \multirow{5}{*}{$\begin{array}{l}\text { After } \\
\text { intervention }\end{array}$} & Definitely C.S. & 3.1 & 1 & 0.0 & 0 & 3.2 & 1 & \multirow{5}{*}{$\begin{array}{l}X^{2}=4.00 \\
p=0.135 *\end{array}$} \\
\hline & Probably C.S. & 12.5 & 4 & 9.7 & 3 & 35.5 & 11 & \\
\hline & Probably NVD & 43.8 & 14 & 41.9 & 13 & 25.8 & 8 & \\
\hline & Definitely NVD & 40.6 & 13 & 48.4 & 15 & 35.5 & 11 & \\
\hline & Total & 100.0 & 32 & 100.0 & 31 & 100.0 & 31 & \\
\hline \multicolumn{2}{|c|}{ Inter-group test results $* *$} & \multicolumn{2}{|c|}{$\mathrm{p}=0.004$} & \multicolumn{2}{|c|}{$\mathrm{p}=0.006$} & \multicolumn{2}{|c|}{$\mathrm{p}=0.207$} & \\
\hline
\end{tabular}

* Kruskal-Wallis test, ** Wilcoxon signed-rank test; C.C.: Cesarean section; NVD: Normal vaginal delivery

Table 2. The attitude towards $\mathrm{C}$-section score mean and variance before and after the intervention with separation of the three studied groups and their comparison test

\begin{tabular}{|l|l|l|l|l|}
\hline $\begin{array}{l}\text { Attitude towards cesarean } \\
\text { delivery score }\end{array}$ & Optimism training & $\begin{array}{l}\text { Training the benefits } \\
\text { of NVD }\end{array}$ & Control & $\begin{array}{l}\text { Intra-group } \\
\text { test results }\end{array}$ \\
\hline Before intervention & $36.3 \pm 13.1$ & $34.9 \pm 10.9$ & $63.6 \pm 12.2$ & $\mathrm{p}=0.973 *$ \\
\hline After intervention & $29.5 \pm 9.6$ & $29.5 \pm 9.9$ & $37.8 \pm 10.9$ & $\mathrm{p}=0.002 * *$ \\
\hline $\begin{array}{l}\text { Difference between before } \\
\text { and after intervention }\end{array}$ & $-6.8 \pm 8.8$ & $-5.5 \pm 5.3$ & $1.2 \pm 3.8$ & $\mathrm{p}<0.001 *$ \\
\hline Inter-group test results & $\mathrm{p}=0.001 * * *$ & $\mathrm{p}<0.001 * * * *$ & $\mathrm{p}=0.092 * * *$ & \\
\hline
\end{tabular}

* Kruskal-Wallis test, $* *$ Analysis of variance (ANOVA), *** Paired-samples t-test, *** Wilcoxon signed-rank test

After the intervention, the three groups showed significant statistical differences in terms of attitude towards Csection score $(\mathrm{p}=0.002)$. The results of a Bonferroni test as a subsequent procedure for variance analysis showed that the group receiving both optimism and NVD advantages education as well as the group receiving only the NVD advantages education demonstrated significant decrease in attitude towards $\mathrm{C}$-section score in comparison with the control group $(\mathrm{p}=0.002)$. In order to assess the attitude towards NVD score before and after the intervention, variance analysis (for normally distributed variables) and Kruskal-Wallis (for non-normally distributed variables) 
tests were used between the three groups. The results elucidated that after the intervention, significant statistical differences were found in attitude towards NVD score $(p<0.001)$. The two-by-two comparison test results using Mann-Whitney test and its p-value amount correction by Bonferroni method, showed that the people in optimism and NVD advantages education group demonstrated significant increase in attitude towards NVD score in comparison with the other two groups $(\mathrm{p}<0.001)$ (Table 3$)$.

Table 3. The attitude towards NVD score mean and variance before and after the intervention with separation of the three studied groups and their comparison test *

\begin{tabular}{|l|l|l|l|l|}
\hline $\begin{array}{l}\text { Attitude towards cesarean } \\
\text { delivery score }\end{array}$ & Optimism training & $\begin{array}{l}\text { Training the benefits of } \\
\text { NVD }\end{array}$ & Control & $\begin{array}{l}\text { Intra-group } \\
\text { test results }\end{array}$ \\
\hline Before intervention & $48.0 \pm 13.1$ & $52.0 \pm 8.5$ & $47.6 \pm 10.3$ & $\mathrm{p}=0.209$ \\
\hline After intervention & $49.0 \pm 12.3$ & $55.3 \pm 7.2$ & $67.8 \pm 3.1$ & $\mathrm{p}<0.001$ \\
\hline $\begin{array}{l}\text { Difference between before } \\
\text { and after intervention }\end{array}$ & $1.0 \pm 1.8$ & $3.3 \pm 4.8$ & $20.2 \pm 11.1$ & $\mathrm{p}<0.001$ \\
\hline Inter-group test results & $\mathrm{p}=0.064$ & $\mathrm{p}=0.001$ & $\mathrm{p}<0.001$ & \\
\hline
\end{tabular}

* Data were analyzed using Kruskal-Wallis test, Analysis of variance (ANOVA), Paired-samples t-test

\section{Discussion}

The present study has been conducted with the aim of a 'Comparative Study of Teaching Natural Delivery Benefits and Optimism Training on Mothers' Attitude and Intention to Select a Type of Delivery'. Findings of the present study were indicative of a significant association between training groups compared with control group and change of attitude in the subjects. Although, it was suggested by Toghyani et al. (26) that training had no significant effect on women's attitude toward their choice of delivery method. The inconsistency could be due to the fact that there are differences in the educational content, and the emotional state of the participants at the time of the two studies must also be taken into consideration. Furthermore, in the research by Toghyani et al., continuous training did not focus solely on the participants' familiarity with delivery methods and techniques of painless labor, which is inconsistent with our study. However, the impact of educating both the advantages of NVD along with optimism is greater in terms of creating positive attitude towards NVD in comparison with only educating the NVD advantages. Perhaps it can be stated that optimism has been more influential on attitude through improving coping strategies. Although in the present study there was no significant difference in delivery type selection intent between the two groups, the results elucidated that optimism and NVD advantages education caused the selection of NVD to increase by 4.4 times whereas NVD advantages education has increased the selection of this type of delivery by 3.8 times. Probably one of the most important reasons of failure of achieving a proper result is the low sample size. In the current study, the studied group received 6 sessions of education and the rate of NVD increased to $28.2 \%$ in this group after the intervention, which can be as a result of difference in education type as well as increase in number of sessions, which itself can have greater effects on function. In a Fathian et al. study, the results demonstrated that effects of education based on behavioral intention model is greater in terms of knowledge, attitude, intent for delivery type and function, in comparison with the control group (3). The important point of Fathian's study is that among the 4 education sessions, one was also specified to the research units' spouses. This can be influential on the attitude change of pregnant women. The results of this study elucidated improvement in attitude towards NVD which is consistent with the current research. In a study by Shahraki-Sanavi et al. (25), an educational package consisting of three booklets, four cards with encouraging messages regarding natural childbirth, and a CD were issued to participants in the intervention group, along with a 60-minute discussion session. According to the study, behavior of the intervention group changed as much as $26 \%$, and the participants decided (probably or definitely) to select natural delivery (25). It is worth mentioning that the study population and training methods in the research by Shahraki-Sanavi et al. were different to the methods of the present study. Also, in the Shahraki et al. study, participants were women who had decided and intended to select elective C-section, and in terms of gravidity, 56\% of the participants in both groups were primigravida. However, in our study, all the women were nulliparous and had yet to decide which to choose between natural delivery and caesarean section. However, the findings of Shahraki et al. are in line with the results of the current study despite the difference in volume of the subject matters and duration of training. Baron et al. concluded that pessimism is related to C-section increase, while optimism has no effects on C-section rate decrease (23). In the present study, optimism education decreased the C-section selection frequency from $43.8 \%$ to $15.6 \%$. Perhaps, the role of education can be considered as the reason for this difference. In the present study, NVD selection intent rate is higher in the group receiving both optimism and NVD advantages education compared with the one with only NVD advantages education, but the difference has not been statistically 
significant $(\mathrm{p}=0.135)$. The purpose of education during pregnancy was to promote attitude and reduce reque sted Csections by mothers, which has been achieved in the present study.

\section{Study strengths and limitations}

Among the strengths of this study, the following can be listed: the fact that the research units were divided into 3 groups, phone follow up on all research units during the study and maintaining contact with them. Also, optimism education protocol design for pregnant women was conducted for the first time in the country, in this study. A limitation of the current study was the participants' differences in mental ability to learn the educational content, which may have had an effect on their attitude and decisions. However, the random allocation of participants to the study groups controlled this issue to some extent. In addition, participants' information sources regarding natural delivery and C-section (e.g., pamphlets, books, radio, television and other mass media) was moderately controlled.

\section{Conclusions}

Childbirth is an important experience in women's lives. Therefore, mental support during pregnancy is recommended. Since it is possible to play an important role in reducing illnesses and side effects and therefore improving the mothers' health through effective education during pregnancy by improving levels of attitude, and also considering the role of optimism education in decreasing stress and its positive effects on mental health and attitude of individuals, it is recommended that this education is provided for all pregnant women during pregnancy care because it is effective in creating a positive attitude towards natural delivery.

\section{Acknowledgments:}

This paper is a result of a student thesis at Mashhad University of Medical Sciences and is completed with the cooperation of the Evidence-Based Research Center. The University Vice-Chancellor's Office for Research and also all research units and respected personnel of the chosen health centers of Mashhad city are thanked for their cooperation and assistance.

\section{Trial registration:}

The trial was registered at the Iranian Registry of Clinical Trials (http:/www.irct.ir) with the Irct ID: IRCT2015063022995N1.

\section{Funding:}

This trial is funded by Mashhad University of Medical Sciences in collaboration with the Evidence-Based Research Center (Ref. no.: research/930321/1/172).

\section{Conflict of Interest:}

There is no conflict of interest to be declared.

\section{Authors' contributions:}

All authors contributed to this project and article equally. All authors read and approved the final manuscript.

\section{References:}

1) Sharghi A, Kamran A, Sharifi Rad GH. Factors affecting the choice of mode of delivery in nulliparous pregnant women referred to Ardabil health centers. Journal of the Research public health. 2011; 3(7): 36473.

2) Bani S, Seyyed Rasouli A, Ghoraishi Shams T, Ghoojazadeh M, Hasan Poor SH. Preferrenced perpetrators of Delivery about their delivery and type of delivery offered to pregnant women. Journal of Tabriz Nursing and Midwifery. 2012; 5(11): 629-635

3) Fathian Z, Sharifi Rad G, Hasanzade A. Study of the effects of Behavioral Intention Model education on reducing the cesarean rate among pregnant women of Khomeiny-Shahr. Journal of East Medico. 2006; 9(2): 123-31.

4) Darvishi A, Mortazavi S, Nejat S, Halakubi K. Women's views and experiences of Obstetricians and Gynecologists and the chosen delivery method. Journal of East Medico. 2011; 8(1): 1-9.

5) Salehian T, Delaram M, Safdari F, Jazayeri F. Knowledge and attitudes of delivery in pregnant women referred to health centers of Shahrekord in 1385-1386. Sunrise Health. 2007:6(2): 1-10.

6) Ghaffari M, Sharifirad GH, Akbari Z, Khorsandi M, Hassanzadeh A. Health Belief Model-Based Education \& Reduction of Cesarean among Pregnant Women: An Interventional Study. Journal of Health System Research. 2011: 7(2): 200-8. 
7) Abedian Z, Navaei M, Jafari SH, Ebrahimzade S. Compare two teaching methods, role playing and lectures on knowledge, attitude and performance of primiparous women. Journal of Obstetrics \& Gynecology and Infertility of iran. 2011; 15(1): 25-35.

8) Ali Akbari S, Bahrami N, Tork zahrani SH. Alavi majd H. Investigating the Attitude \& knowledge of women toward of mode of delivery in Dezfool. Journal of Shahid Beheshti Nursing and Midwifery. 2007; 62(18): 24-30.

9) Amiri M, Raee M, Chaman R, Rezaee N. Factors related to the type of delivery in women who Sciences Medical Shahrood. Journal of Razi Medical Sciences. 2013; 106(20): 1-8.

10) Farahani A, Shavazi A. Caesarean section change trends in Iran and some demographic factors associated with them in the past three decades. Journal of Fasa University of Medical Sciences. 2012; 2(3): 127-34.

11) Naseri Asl M, Poorreza A, Akbari F, Rahimi A. Investigated the effect of economic variables, social impact on the incidence of cesarean delivery Hospitals in Ardebil 1388. Journal of Health and hygiene. 2013; 4(4): $349-56$.

12) Etghaee M, Noohi A, khajepoor M. Investigating the Attitude towards labor pain and choose the mode of delivery in pregnant women referred to health care centers in Kerman. Journal of Kerman Nursing and Midwifery. 2009; 41(19): 10-36.

13) Tofighi Niaki M, Behmanesh F, Mashmuli F, Azimi H. The effect of prenatal group education on knowledge, attitude and selection of delivery type in primiparous women. Iranian Journal of education in Medical Sciences. 2010; 10(2): 124-30.

14) Sharifirad G, Fathian Z. Survey of pregnant women view than vaginal and cesarean delivery based on behavioral intention model. Journal of Illam University of Medical Sciences. 2007; 1(15): 19-23.

15) Lashgari M, Delavari S, Markazi Moghaddam N, Gorouhi F. Effect of training programs of pregnant women on their delivery type selection: A single blind, randomized control trial. Journal of Tehran Army University of Medical Sciences. 2005; 3(12): 79-84.

16) Mesgarzade M, Orujlu S, Ebrahimi M, Baghaie R. Survuy of mother's satisfaction from provide care in delivery unit in the Khoy Qamar Bani Hashem hospital in 2012. Journal of Orumieh Nursing and Midwifery Faculty. 2014; 12(10): 919-25.

17) Gamble JA, Creedy DK. Women's preference for a cesarean section. Birth. 2001; 28(2): 10-101. doi: 10.1046/j.1523-536X.2001.00101.x.

18) Navaei M. Compare two teaching methods, role playing and lectures on knowledge, attitude and performance of primiparous. [Dissertation]. Mashhad Nursing and Midwifery Faculty, University of Medical Science. 2010.

19) Waldenstrom U, Hildingsson I, Ryding EL. Antenatal fear of childbirth and its association with subsequent caesarean section and experience of childbirth. BJOG. 2006; 113(6): 38-46. doi: 10.1111/j.14710528.2006.00950.x. PMID: 16709206.

20) Madani Poor K, Hagh Ranjbar F, Kakavand A, Sanaee Zaker B. The relationship between attachment style with optimism and loneliness feeling in Students 9-12 years in Karaj. Journal of Health and Psychology. 2011; 1(1): 93-110.

21) Lobel M., Devincent C. J., Kaminer A., Meyer B. A. The impact of personal maternal stress and optimistic disposition on birth outcomes in medically high risk woman. Health Psychology 2000; 19: 544-553. doi: 10.1037/0278-6133.19.6.544.PMID: 11129357.

22) Carver CS, Gaines JG. Optimism, pessimism and postpartum depression. Cognitive Therapy and Research 1990; 4: 449-462.

23) Bar-On S. Benyamini Y. Ebrahimoff M. Many A. Mother knows best? Comparing primiparous parturient' expectations and predictions with actual birth outcomes. Journal of Perinat2013: 1-5.

24) Moyer C, Elsayed Y. Zhu Y, Wei Y, Is generalized maternal Optimism or Pessimism during Pregnancy Associated with Unplanned Cesarean Section Deliveries in China? Journal of Pregnancy 2010: 1-10. doi: 10.1155/2010/754938.PMID: 21490743 PMCID: PMC3065811.

25) Shahraki Sanavi F, Navidian A, Rakhshani F, Ansari Moghaddam A. The effect of education on base the Theory of Planned Behavior toward normal delivery in pregnant women with intention elective cesarean. Hormozgan University of Medical Sciences 2012; 6(17): 531-539. [Text in Persian]

26) Toghyani R, Ramezani MA, Izadi M, Motie $Z$. The effect of prenatal care group education on pregnant mothers' knowledge, attitude and practice. Iranian Journal of Medical Education. 2008; 7(2):317-324 (Persian). 